\title{
The Benefits and Barriers for Promoting Bamboo as a Green Building Material in China- An Integrative Analysis
}

\author{
Liyin Shen ${ }^{1,2}$, Junsi Yang ${ }^{1,2} \mathbb{C}$, Rong Zhang ${ }^{1,2, *}$, Changzhuan Shao ${ }^{3}$ and Xiangnan Song 4 \\ 1 School of Construction Management and Real Estate, Chongqing University, Chongqing 400044, China; \\ shenliyin@cqu.edu.cn (L.S.); junsi.yang@foxmail.com (J.Y.) \\ 2 International Research Center for Sustainable Built Environment, Chongqing University, \\ Chongqing 400044, China \\ 3 School of Architecture, The Chinese University of Hong Kong, Hong Kong, China; \\ shaochangzhuan@163.com \\ 4 School of Management, Guangzhou University, Guangzhou 510006, China; sxnsunny89@163.com \\ * Correspondence: zhang.rong@cqu.edu.cn
}

Received: 5 March 2019; Accepted: 24 April 2019; Published: 28 April 2019

\begin{abstract}
Bamboo is commonly considered as a green, environmentally friendly material. However, it appears that bamboo finds limited application in the form of green building materials in the Chinese construction sector. In order to explain this phenomenon and promote the material's application, this study summarizes the benefits of applying bamboo materials and presents an analysis on barriers affecting the effective application of bamboo materials in this specific building sector. Research data are collected from both literature surveys and semi-structured interviews with a group of carefully selected experts from the Chinese building sector. Fifteen characteristic barriers are identified, such as ineffective action by government departments. An integrative analysis is conducted, including investigation on the hierarchy structure among characteristic barriers using the interpretive structural modeling (ISM) method and the classification of barriers from a driving-driven perspective using the Cross-impact Matrix Multiplication Applied to Classification (MICMAC) technique. This classification provides a different profile for the characteristic barriers from that of traditional barrier analysis methods. The findings provide valuable references for helping policy makers and practitioners adopt effective policies and measures to promote the application of bamboo for green materials in building sector.
\end{abstract}

Keywords: bamboo; green building material; characteristic barriers; interpretive structural modeling (ISM); Cross-impact Matrix Multiplication Applied to Classification (MICMAC)

\section{Introduction}

The construction industry is commonly accountable for various environmental problems [1]. The most common construction systems employed in almost every project are energy-intensive and emit high levels of greenhouse gases such as $\mathrm{CO}_{2}$, as they mainly adopt concrete in the form of blocks and/or other structural elements [2,3]. According to the estimations by the Carbon Dioxide Information Analysis Center [4], since 2007 China has become the world's largest $\mathrm{CO}_{2}$ emitter. A study by Nandi [5] showed that the emissions from China represented as much as $68 \%$ of total global emission increase between 2000 and 2010. Others commented that China's $\mathrm{CO}_{2}$ emissions have significant influences on global climate change [6]. Therefore, promotion of green building materials in China is not only a local issue but has significant positive impact on global climate.

Bamboo is a typical green material that is fast-growing, lightweight, has high strength, and is environmentally friendly. For example, carbon emissions can be reduced by using bamboo as 
construction materials. According to previous studies, bamboo can sequester high levels of $\mathrm{CO}_{2}$ during its growth process and can potentially store $\mathrm{CO}_{2}$ over the life span of construction projects [7-10]. These studies support findings that proper use of bamboo as a green building material can contribute to $\mathrm{CO}_{2}$ reduction and, in turn, to the reduction of climate change speed.

Traditionally, bamboo has been used largely in simple ways, although it is environmentally friendly and has been used for building materials for thousands of years. For example, in India, Nepal, and Bhutan, many bamboo homes called "Ekra" are hundreds of years old and are commonly in forms of traditional vernacular architecture. Bamboo woven walls are used in these homes to provide a basic building envelope [11]. These simple and traditional ways of using bamboo, however, are phasing out in line with the development of steel and concrete materials [12].

In recent years, nevertheless, promotion of sustainable construction is called for in the development and use of green building materials [13], and bamboo is widely considered a typical type of green material. In line with this background, application of bamboo as a green building material has been increasingly occurring internationally [14]. There are increasing numbers of successful bamboo applications in the construction sector globally, such as the bamboo ceiling in Madrid International Airport in Spain, the bamboo floors in Clinton Library in the United States, the Tokyo Dong Wu Department in Japan, and the BMW exhibition hall and the IBM headquarters in Germany [15]. Nurdiah [16] reported that many pedestrian bridges are built with bamboo in Columbia, schools are built with bamboo in Indonesia, and bamboo scaffoldings are commonly used in Hongkong. Many aseismic buildings in the earthquake-stricken area of Wenchuan, Sichuan in China are mainly built with bamboo and wood [17]. Many governments in the world have already introduced various policy measures to promote application of bamboo for building materials. In Europe, various programs for promoting bamboo materials have been introduced, for example, "Sustainable Management and Quality Improvement of Bamboos and Products [18] and "New Bamboo Engineered Bio-material for Sustainable Building Components" [19] in countries such as the United Kingdom, Germany, Belgium, and Italy. The government in India launched the "National bamboo mission" in 2006 [20]. The Chinese government has been promoting bamboo materials through introducing a number of guideline documents [12], for example, the program of "Replacing wood with bamboo" issued in 2005. The subject of how to produce and use bamboo as a building material was included as a key research area in the Chinese 13th Five-Year Plan [21].

However, it seems that the effectiveness of using bamboo as a green building material is not significant in China, where there is a large amount of natural bamboo. It was estimated that China has 5.38 million $\mathrm{hm}^{2}$ of bamboo forest area [22]. The application of bamboo as a building material in China is far less than that in other countries [11]. Liu et al. [23] pointed out that the use of bamboo materials in China is mostly limited to simple handmade products, such as baskets, mats, and curtains. There are few enterprises specialized in the production and application of bamboo building materials. Previous studies have suggested various obstacles to the application of bamboo for building materials in China such as the absence of standards [23] and the traditional bias against bamboo materials [24]. It is interesting to note that, although green building has been promoted since 1992 in China, few bamboo materials have been used in the promotion process $[25,26]$.

China will continue its urbanization mission for the coming future with 2 billion square meters of new buildings to be built every year [27]. Considering the huge scale of future building works in China, effective application of bamboo as a green building material will make significant contributions to the promotion of sustainable construction. It is very important to understand the barriers that prevent bamboo from being used in this huge building sector. Without proper understanding of these barriers, application of bamboo in China will remain limited, the value of green nature embodied in bamboo materials will be virtually wasted, and the potential of using bamboo for promoting sustainable construction will be overlooked. Therefore, it is essential to examine these barriers. Based on which proper measures can be taken to address these barriers, the effective application of bamboo can be promoted effectively. 
Previous studies have investigated various barriers affecting the application of bamboo materials from different perspectives, but they mainly concentrated on single perspectives such as physical or chemical properties of bamboo. Some researchers suggested that the main barriers affecting the application of bamboo were technology related, such as fire resistance [28,29], lack of research funding [11,30], insect resistance, and durability of bamboo [23,31]. Other studies have analyzed barriers in the process of using bamboo, such as a lack of awareness among stakeholders about the socioeconomic importance of bamboo resources [28], lack of consensus and cooperation among government departments [23], lack of standards and specifications in the bamboo industry [24], and the high costs involved in processing bamboo materials [30]. There are several studies that discuss barriers hindering the application of bamboo from an educational perspective, and these highlighted barriers include biased cognition about the durability and strength of bamboo materials [24], lack of teaching materials about bamboo applications [12], lack of training for industrial personnel [32], and lack of interdisciplinary research on bamboo materials [11]. Some researchers addressed policy-related barriers affecting the application of bamboo in the Chinese building sector such as the absence of code of practice in the bamboo industry, lack of incentive policy [30], and the absence of certification mechanisms for bamboo materials [32].

Existing literature provides some insight on barriers affecting the application of bamboo materials in the construction sector, but they are largely in fragmented perspectives. It is considered important to understand these barriers collectively. In addition, the barriers identified in previous studies are very limited. For example, weak roles and ineffective action by governments have not been considered. Furthermore, integrated relationships between barriers have not been examined. In fact, integration between barriers has a significant impact on the application of bamboo materials.

Therefore, this paper aims to summarize the benefits of applying bamboo materials, conduct a comprehensive investigation on the barriers affecting application of bamboo materials in the context of the Chinese building sector, and examine the integrated relationships between these barriers. Investigation results are expected to help concerned stakeholders build a better understanding of the application of bamboo as a green building material and develop effective measures for applying the materials in practice. The rest of this paper is organized as follows: Section 2 will discuss the benefits of bamboo for green building materials. Section 3 will describe the research methods adopted in this study. Characteristic barriers affecting the application of bamboo in China will be presented in Section 4. The significance of characteristic barriers will be discussed in Section 5. Section 6 will produce a hierarchy structure to show the integrated relationships between the identified barriers with the interpretive structural modeling (ISM) method and intricate relationships between barriers in the hierarchy will be further analyzed from driving-driven perspective by employing the Cross-impact Matrix Multiplication Applied to Classification (MICMAC) technique. Discussion and conclusions will be given in Section 7 .

\section{Benefits of Bamboo for Green Building Materials}

It is important to understand the benefits of using bamboo for green building materials in order to promote its application. Various existing studies have examined the benefits of bamboo, and these typical studies are listed in Table 1.

Table 1. Typical literature on studying the benefits of bamboo for green building materials.

\begin{tabular}{cllll}
\hline References & & Benefits Identified & References & \multicolumn{1}{c}{ Benefits Identified } \\
\hline & $\bullet$ & Fast growth in raw materials & & Less energy use in \\
& $\bullet$ & Shorter rotation & & production process \\
Fang et al. [33] & $\bullet$ & Higher mechanical strength & Yu et al. [34] & consume carbon \\
& $\bullet$ & Abundant and & emission during the \\
& & sustainable resource & & growth process \\
\hline
\end{tabular}


Table 1. Cont.

\begin{tabular}{|c|c|c|c|}
\hline References & Benefits Identified & References & Benefits Identified \\
\hline Puri et al. [35] & $\begin{array}{ll}\text { - } & \text { Economical advantage } \\
\text { because of shorter rotation } \\
\text { - } & \text { Abundant resource } \\
\text { - } & \text { Consumption of } \mathrm{CO}_{2} \text { and } \\
\text { release of oxygen } \\
\text { - } \quad \text { Less energy use in } \\
\text { production process } \\
\text { - Pliable, lightweight, excellent } \\
\text { tensile strength } \\
\text { Low cost }\end{array}$ & Mahdavi et al. [36] & $\begin{array}{ll}\text { - } & \text { Renewable } \\
\text { - } & \text { Biodegradable } \\
\text { - } & \text { Lequestering carbon } \\
\text { - } & \text { Creating less pollution } \\
& \text { in production }\end{array}$ \\
\hline Escamilla et al. [9] & $\begin{array}{l}\text { - Sequester high levels of } \mathrm{CO}_{2} \\
\text { - Job creation and the } \\
\text { improvement of income } \\
\text { levels in rural and } \\
\text { urban areas }\end{array}$ & Seixas et al. [37] & $\begin{array}{l}\text { - } \quad \text { Good economic potential } \\
\text { - } \quad \text { Abundance } \\
\text { Lightweight }\end{array}$ \\
\hline Laroque [1] & $\begin{array}{ll}\text { - } & \text { Great mechanical and } \\
\text { - } & \text { Growthetical properties } \\
\text { - } & \text { Good resistance } \\
\text { - } & \text { against bending } \\
\text { - } & \text { Environmensive } \\
\text { - } & \text { Lightweight }\end{array}$ & Shah et al. [38] & $\begin{array}{ll}\text { - } & \text { Light, strong, and versatile } \\
\text { - } & \text { Environmentally friendly } \\
\text { - } & \text { Accessible to the poor } \\
\text { - } & \text { Renewable resource } \\
\text { - } & \text { Fast growing }\end{array}$ \\
\hline Opoku et al. [39] & 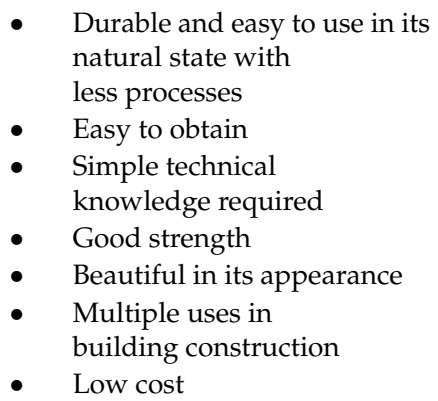 & Chang et al. [40] & $\begin{array}{ll}\text { - } & \text { Carbon storage } \\
\text { - } & \text { Mitigating the effect of } \\
\text { - } & \text { Envimate change } \\
\text { - } & \text { Fast growing } \\
\text { - } & \text { Energy conservation } \\
\text { - } & \text { Reduction of } \mathrm{CO}_{2} \text { emissions } \\
\text { - } & \text { Biochemical fuel substitution } \\
\text { - } & \text { Short rotation age } \\
\text { - } & \text { High tensile strength }\end{array}$ \\
\hline
\end{tabular}

By reviewing these studies, the benefits can be classified into five categories: (1) large-scale and fast growth, (2) lightweight and high strength, (3) low-cost, (4) environmentally friendly, and (5) social benefit. The details of these benefits are elaborated as follows.

Large-scale and fast growth: Bamboo is one of the fastest growing and widely distributed plants on Earth [1]. It is mainly distributed in three regions: Asia-Pacific, the Americas, and Africa, and the Asian-Pacific is the largest in terms of volume of the materials. According to Scurlock [14], there are more than 180,000 km² of bamboo forest in Asia (half the size of Germany). Bamboo also exhibits a short rotation age. It has a higher accretion rate than timber and can be logged in every three to five years. In addition, bamboo harvesting is more acceptable to the general public than timber harvesting [40]. Because of its large scale and rapid growth, bamboo is a typical renewable and green material in the building sector.

Lightweight and high strength: Bamboo has been used for building materials in the construction of millions of houses across the world in the past thousands of years, although these households are largely in simple structure [11]. This material is lightweight and high-strength, thus it is an alternative and renewable construction material, which has earned the name of 'vegetal steel' [41]. According to Laroque [1], bamboo is even stronger than steel in tension and bending in certain cases. Other studies show that bamboo is often used as an alternative to timber and plastic for drainage pipes and storage 
facilities. Application of these materials offers resilient structures that can withstand natural disasters such as high-velocity winds or earthquakes [12,42].

Low cost: It is commonly appreciated that the cost of raw bamboo materials is low [39]. The material is used to build simple houses, particularly in many less-developed areas of the world; thus, it is also called "wood of the poor". In India, for example, there are low-cost houses with reinforced and prefabricated bamboo wall panels, and it has been demonstrated that the cost of these bamboo buildings is very low [35].

Environmentally friendly: Application of bamboo as building materials can not only reduce the pressure of depleting non-renewable building materials, but it also contributes to energy saving, reduction of $\mathrm{CO}_{2}$ emissions, and the increase of carbon storage [34,43,44]. These characteristics contribute directly to a better environmentally friendly performance. Lu et al. [45] pointed out that bamboo planted on sloping farmland has positive effects on water conservation and soil erosion control. Others appreciated that the application of bamboo as building material can induce lower negative environmental impacts compared to common building materials such as concrete [10,44].

Social benefits: In referring to socially and economically underdeveloped areas where, at the same time, bamboo resources exist, the application of bamboo can help local laborers have more job opportunities and increase their incomes. Social benefits of employing less-educated laborers in the bamboo industry can be gained, as the skills needed for processing bamboo materials is low $[39,46]$.

In summary, the above discussed benefits from using bamboo can contribute to the promotion of sustainable construction. Nevertheless, it appears that these benefits have not been effectively utilized in the contemporary Chinese building sector. Therefore, this study investigates the barriers that restrict these benefits from being effectively utilized.

\section{Research Methods}

To achieve the aim of this study, an integrative analysis was conducted by investigating hierarchy structure and classifying the barriers from a driving-driven perspective. The detailed research methods were planned as follows.

\subsection{Identifying Characteristic Barriers}

This research work started with identifying characteristic barriers that restricted bamboo materials from being applied in the promotion of sustainable construction. Barrier identification was usually conducted by using a content analysis method [47]. This method is a proven effective method, especially in the sociological research field, for collecting and analyzing data to identify research problems from literature content, including websites, databases, official documents, and other existing studies. In this study, the research team examined a wide range of literature, news reports, official documents, and a number of authoritative literature databases such as Web of Science, China National Knowledge Infrastructure (CNKI) database, the official website of International Network for Bamboo and Rattan (INBAR), and the official website of National Forestry and Grassland Administration. Accordingly, a comprehensive list of barriers affecting the application of bamboo in the context of China was formulated through content analyses of the literature collected.

However, barriers identified only through content analysis have limitations, such as the existence of a high correlation and synonyms between barriers [48]. For example, the barriers "fire hazard of bamboo" and "fire resistance of bamboo" are synonymous. Therefore, semistructured interviews with a group of selected experts were organized to assist in selecting characteristic barriers. These experts had practical experience and knowledge of bamboo materials in the Chinese building sector.

\subsection{Integrative Analysis}

Integrative analysis was conducted to examine interrelations between the identified characteristic barriers through the following two processes. 


\subsubsection{Establishing the Hierarchy Structure between the Characteristic Barriers}

The hierarchy structure between the identified characteristic barriers will be established by employing the interpretive structural modeling (ISM) method. Sage [49] introduced the ISM method for explaining the complex relationships between variables. This method has been widely used for studying and analyzing relationships between different variables in a complex system $[48,50]$.

Other traditional methods for analyzing the hierarchy structure between barriers include mean value and weighted score, but they cannot provide insight on the intricate relationships among barriers. Furthermore, traditional methods usually require the collection of data from a large sample of questionnaire surveys [51,52]. As such, it was difficult to receive a large number of samples because there were not many experts in the Chinese building sector with sufficient knowledge and experience in applying bamboo as a building material. For mitigating this limitation, the ISM method was adopted, which emphasized the quality of responses in the survey process instead of quantity. Ravi and Shankar [53] opined that the number of quality experts did not have to be large in applying ISM, for example, it could be as few as two experts.

\subsubsection{Barrier Classification from a Driving-Driven Perspective}

The Cross-impact Matrix Multiplication Applied to Classification (MICMAC) technique was used to classify identified barriers based on the measurements of driving power and dependence power. This method was developed by Duperrin and Godet [54] to study the diffusion of barrier impacts through reaction paths and loops and develop the hierarchies between barriers. According to the MICMAC method, some barriers have driving power, others have dependence power (or driven power). Classifying these two types of barriers can present a clear profile about the intricate relationships between the barriers $[50,55]$.

The major steps of integrative analysis by using ISM and MICMAC are presented in Figure $1[47,56]$.

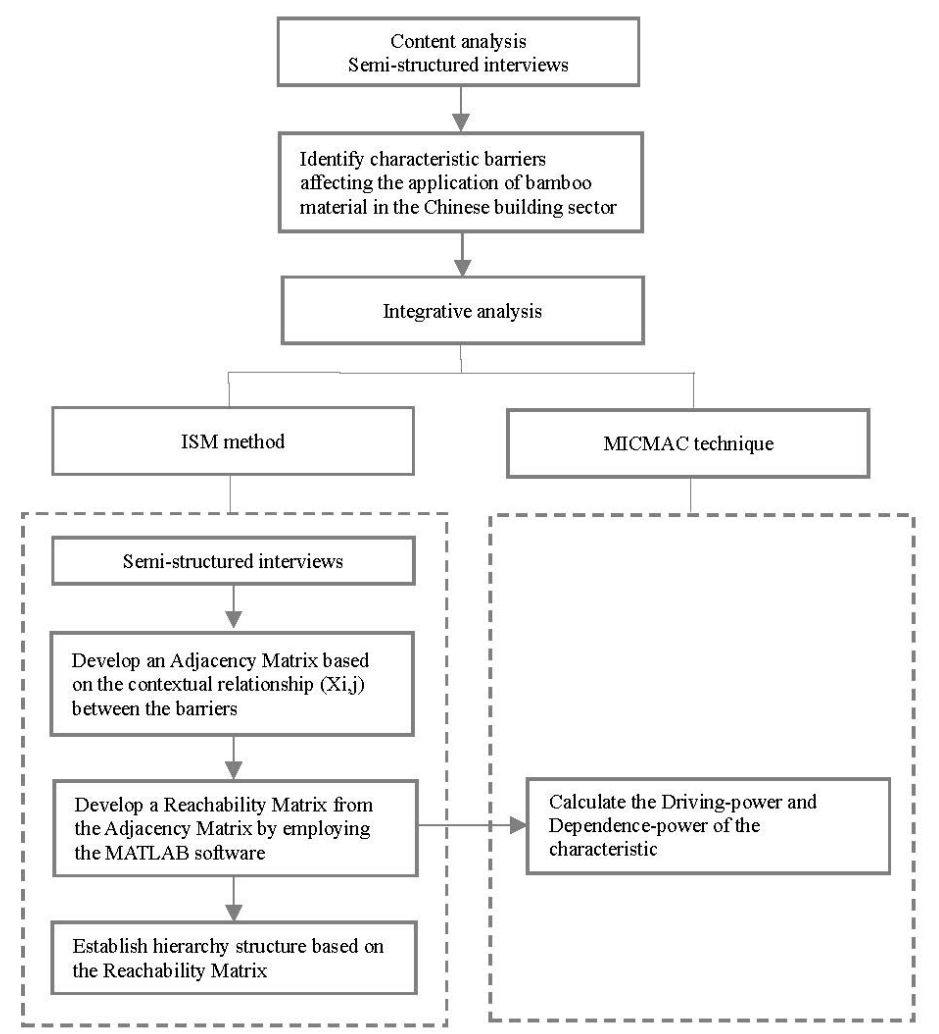

Figure 1. Procedures in applying interpretive structural modeling (ISM) and the Cross-impact Matrix Multiplication Applied to Classification (MICMAC) techniques. 


\section{Characteristic Barriers Affecting the Application of Bamboo for Green Building Materials}

In order to find out the characteristic barriers affecting the application of bamboo, a comprehensive content analysis was conducted. As a result, a list of typical literature that addressed various barriers was found [11,12,23,24,28-32,36,39,42,57-59].

By reviewing these research works, these barriers were classified into three categories: technology-related, application-related, and policy-related barriers. Technology-related barriers were those encountered in the process of theoretical and experimental research on bamboo materials, such as mechanical strength and durability. Application-related barriers referred to the problems that industries or enterprises encountered in practice, such as low level of industrialization for production, high material cost, and lack of skills. Policy-related barriers referred to policy measures or mechanisms, such as incentive policies, that promoted or regulated development of the bamboo industry. Details of these barriers are listed in Table 2.

The representativeness of the barriers in Table 2 was further investigated from the perspective of the significance of their constraints in the application of bamboo, for which a semistructured interview survey was conducted.

As the quality of the survey depended on the quality of the interviewees [3], it was important to ensure that the interviewees were knowledgeable about both bamboo materials and the building sector in China. In order to identify sufficient and effective interviewees, the research team approached officials in relevant governmental departments in China, professors in major universities, and practitioners who had bamboo knowledge and experience. During the survey period of March 2018 to July 2018, the research team visited the International Network for Bamboo and Rattan (INBAR), Forestry Bureau of Anji Country, Zhejiang Province, The Chinese University of Hong Kong, Tsinghua University, and Zhejiang University. The research team conducted discussions with a number of experts and professionals during the conference "Global Bamboo and Rattan Congress 2018" in Beijing in June 2018. The above research efforts led to discussions with 42 interviewees. However, it was found that only 12 of them had sufficient knowledge and experience and could provide effective comments about application of bamboo material in the Chinese building sector. Finally, the authors managed to have in-depth interview discussions with seven of these experts. The details of these seven experts are shown in Table 3. These seven selected experts all had good knowledge of and practical or research experience with bamboo. Their comments and opinions were considered effective for analysis in this research.

These seven experts were invited to judge which barriers in Table 2 were characteristic and representative in reflecting the constraints to the application of bamboo in the Chinese building sector. In order to facilitate effective judgement among the experts, the following questions were designated for their responses during the discussions:

1. Are any barriers provided in the list not applicable?

2. Are the expressions of the barriers proper and understandable? If not, how to revise?

3. Are there any synonymous barriers? If so, which should be integrated?

4. Which barriers are representative in influencing the application of bamboo materials in building sectors? And why?

5. In addition to the barriers given in Table 2, are there other barriers important but missed? If so, please help to list them.

Experts were requested to judge the significance of representativeness of each barrier. Having received the responses from the interview experts, the authors carefully analyzed the feedback. As a result, a list of 15 barriers, as shown in Table 4, were filtered as characteristic barriers that restricted bamboo application in the Chinese building sector. 
Table 2. Barriers affecting bamboo application in the building sector.

\begin{tabular}{|c|c|c|}
\hline Category & Barriers Affecting & Bamboo Application \\
\hline Technology Related Barriers & $\begin{array}{l}\text { - Lack of systematic experimental research } \\
\text { - Little research on restoring force model and deformation } \\
\text { - } \quad \text { Lack of calculation theory and design method } \\
\text { - } \quad \text { Lew studies on seismic performance } \\
\text { - } \quad \text { Single geometric shape } \\
\text { - } \quad \text { Less reliable in connection } \\
\text { - Moth, corrosion, and mildew } \\
\text { - } \quad \text { Single perspective of appearance } \\
\text { - Little in-depth study of material properties }\end{array}$ & $\begin{array}{l}\text { - } \quad \text { Lack of study on fire resistance } \\
\text { - } \quad \text { Lack of research and innovation about connection methods } \\
\text { - } \quad \text { Lack of precautions for moisture and dimensional stability } \\
\text { - } \quad \text { Poor adhesives } \\
\text { - } \quad \text { Ress reliable in connections } \\
\text { - } \quad \text { Poor durability } \\
\text { - } \quad \text { Difficulty in forming strong joints } \\
\text { - } \quad \text { Hifficulty in quality control } \\
\text { - } \quad \text { Inadequate bamboo processing techniques } \\
\text { - } \quad \text { No software to assist analysis and design }\end{array}$ \\
\hline Application Related Barriers & $\begin{array}{l}\text { - Lack of awareness among stakeholders about the socioeconomic } \\
\text { - } \quad \text { Low level of industrialization for production } \\
\text { - } \quad \text { Lack of construction norms } \\
\text { - } \quad \text { Lack of recognition and policy incentives from the government } \\
\text { - Lack of relevant design specifications and standards } \\
\text { - Lack of relevant laws and regulations } \\
\text { - Lack of industrial planning and marketing planning for } \\
\text { - } \quad \text { Pamboo application } \\
\text { - } \quad \text { Lack of research funds for bamboo building materials } \\
\text { - } \quad \text { Lack of leading enterprises } \\
\text { - Lack of bamboo materials market } \\
\text { - Lack of technology energy saving in the application of bamboo }\end{array}$ & 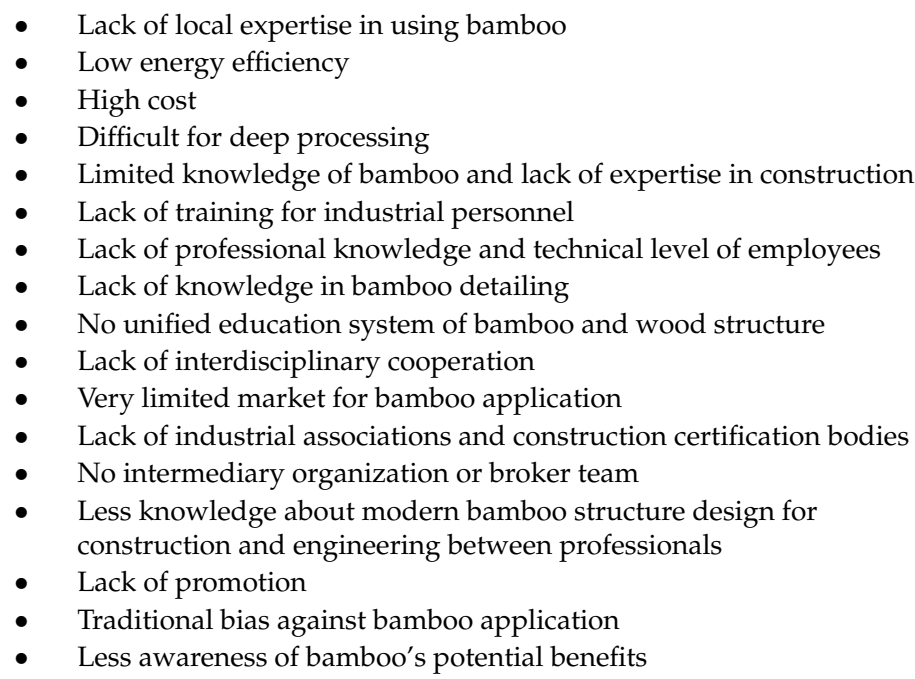 \\
\hline Policy Related Barriers & $\begin{array}{l}\text { - Lack of code of practice in the bamboo industry } \\
\text { - Lack of incentive policy }\end{array}$ & $\begin{array}{l}\text { - No mechanism for technology transfer } \\
\text { - No certification mechanism for bamboo materials }\end{array}$ \\
\hline
\end{tabular}


Table 3. Interview participants.

\begin{tabular}{|c|c|c|c|c|}
\hline Interviewee Code & Work Organization & Job Position & Interview Venue & Interview Method \\
\hline $\mathbf{A}$ & $\begin{array}{l}\text { International Network } \\
\text { for Bamboo and Rattan }\end{array}$ & $\begin{array}{l}\text { Task Force } \\
\text { Coordinator }\end{array}$ & Beijing & Face-to-face \\
\hline B & Zhejiang University & Professor & Zhejiang & Face-to-face \\
\hline $\mathrm{C}$ & $\begin{array}{l}\text { International Bamboo } \\
\text { Architecture Biennale }\end{array}$ & Curator & Shanghai & Face-to-face \\
\hline D & $\begin{array}{c}\text { The Chinese University } \\
\text { of Hong Kong \& } \\
\text { Tsinghua University }\end{array}$ & Doctoral Candidate & Hongkong & Face-to-face \\
\hline E & $\begin{array}{l}\text { Kunming Architectural } \\
\text { Design \& Research } \\
\text { Institute Co., Ltd. }\end{array}$ & $\begin{array}{l}\text { Deputy Chief } \\
\text { Engineer }\end{array}$ & Kunming & Face-to-face \\
\hline $\mathbf{F}$ & $\begin{array}{l}\text { Anji Zhujing Bamboo } \\
\text { Technology co., Ltd. }\end{array}$ & Chairman & Zhejiang & Face-to-face \\
\hline G & $\begin{array}{c}\text { Ganzhou sentai Bamboo } \\
\text { Co., Ltd. }\end{array}$ & General Manager & Jiangxi & Face-to-face \\
\hline
\end{tabular}

Table 4. Characteristic barriers restricting bamboo application in the Chinese building sector.

\begin{tabular}{cc}
\hline & Representatives Barriers \\
\hline B1 & Durability \\
B2 & Knowledge about bamboo application \\
B3 & Industrialization for production \\
B4 & Ineffective action by government departments \\
B5 & Standards and specifications \\
B6 & Enterprise participation \\
B7 & Research and development (R\&D) \\
B8 & Production Costs \\
B9 & Education \\
B10 & Traditional bias against bamboo application \\
B11 & Limited market for bamboo application \\
B12 & Certification mechanism for bamboo materials \\
B13 & Code of practice in bamboo industry \\
B14 & Incentive policy \\
B15 & Technology transfer mechanism \\
\hline
\end{tabular}

\section{The Significance of Characteristic Barriers in Constraining the Application of Bamboo as a Green Building Material}

\subsection{Durability (B1)}

Durability of bamboo is the primary concern for its application, especially in structural works [58]. Bamboo materials are often prone to moth, corrosion, and mildew in untreated conditions, which leads to damage of the mechanical properties of the materials [60]. Therefore, the material is commonly considered to have poor durability. Expert A echoed in the interview that bamboo material often had a short lifespan because of its poor durability. As further echoed by Expert $G$, the durability of bamboo was a major concern for customers to choose it as building materials. As Expert $G$ further commented, customers would consider using bamboo materials if the materials had a lifespan of more than 20 years, especially for structural works. Nevertheless, there is limited study and technology to support that bamboo durability could enable a workable lifespan of more than 20 years. This is why the barrier 'Durability' is one of the most characteristic barriers in constraining bamboo from being applied in the building sector. 


\subsection{Knowledge About Bamboo Application (B2)}

It appeared that knowledge about bamboo applications was fragmented. There was no systematic theory and method for guiding the design, construction, and maintenance of applying bamboo. In the discussion with Expert D, a case was reported that a plan for building a $20 \mathrm{~m}$ long bamboo bridge was given up because no designer was available who knew how to design the bridge by using bamboo. According to the discussion with Expert $\mathrm{F}$, there was no effective method for maintenance work of bamboo structures. Thus, customers had less confidence in choosing bamboo materials. Both Experts $\mathrm{C}$ and $\mathrm{D}$ pointed out that there was little knowledge about the nature and application of bamboo among the public, which was a major constraint to the promotion of bamboo application.

\subsection{Industrialization for Production (B3)}

Currently there is no industry for processing bamboo materials, thus the production cost is very high. It is commonly appreciated that industrialization can help improve product quality, reduce production cost, cut construction waste, and shorten the construction period [61,62]. Nevertheless, as all the interviewed experts echoed, there was no technology or facility for manufacturing bamboo materials. In other words, the advantage of industrialization, a high production efficiency, cannot be currently utilized in bamboo material applications. Therefore, the material is less applied in practice.

\subsection{Ineffective Action by the Government Department (B4)}

The government is the policy maker and should play a vital role in promoting the application of bamboo materials, especially in the initial stage of promotion. However, as pointed out by Expert A, there was insufficient promotion from government departments. Without this plan, relevant norms and specifications on the application of bamboo materials cannot be established; consequently, the promotion of using bamboo is constrained. Furthermore, as pointed out by Expert A, there was lack of coordination between relevant government departments on the use of bamboo as a green building material. For instance, the National Forestry and Grassland Administration is very supportive of applying bamboo as building materials; they issued the policy paper "National bamboo industry development plan (2013-2020)". However, the Ministry of Housing and Urban-Rural Development and the Ministry of Transport did not have policies to endorse application. This lack of coordination between government departments significantly constrains the promotion of bamboo.

\subsection{Standards and Specifications (B5)}

The quality of bamboo application will be protected if there are proper standards and specifications. Wang [24] suggested that the standards and specifications were the preconditions for bamboo to be used on large scale. Nevertheless, there are no such standards and specifications in China at present. The absence of standards and specifications contributes to the lack of confidence in using bamboo among building clients. Expert $G$ pointed out that there was great resistance on the application of bamboo in the design and construction stages because there were no standards and specifications. Those enterprises who wish to use bamboo have to spend a lot of extra resources to demonstrate that bamboo is feasible and effective for use as a building material. Expert $G$ mentioned that tens of thousands of dollars were needed to present an application demonstration. Liu and Oliver [11] reported that the application of bamboo materials for construction in Europe, Southeast Asia, and South America could be promoted largely because of the development of standards and specifications. Therefore, it is essential to establish standards and specifications in the Chinese construction sector in order to promote development of bamboo application.

\subsection{Enterprise Participation (B6)}

There are very few enterprises that participate in the bamboo material industry in China. According to Expert G, some enterprises realized the potential market of bamboo materials and started to plan 
business in the field, but the number of such enterprises was very small. Lack of enterprise participation leads to lack of vitality in the market, and enterprises will not be attracted to technological innovation. In addition, as pointed out by Expert D, lack of enterprise participation would directly affect production efficiency and cost, and it would further affect the application of bamboo materials. Expert D's team could not even find a factory that specialized in bamboo processing in the local market. This forced the team to spend a lot of time and money on buying processed bamboo from external provinces. It was unanimously acknowledged by all experts that limited enterprise participation was one of the most important constraining barriers in the bamboo construction market.

\subsection{Research and Development (RED) (B7)}

Lack of in-depth research and development $(R \& D)$ is one of the barriers to improving bamboo production efficiency. $R \& D$ in technological processes and equipment for production of bamboo materials can help improve the quality of bamboo materials, reduce labor cost, and improve efficiency. In line with this, the scope of bamboo application can be extended. As pointed out by Expert C, companies and designers need up-to-date knowledge of applying bamboo in order to meet the needs of target customers. At present, R\&D for bamboo products in the building sector is very limited. Expert $C$ further commented that a large number of enterprises could only produce bamboo flooring, bamboo ceiling, and other simple products. Expert $\mathrm{F}$ also emphasized that building projects needed more complex bamboo products (e.g., bamboo partition wall or a multi-layer bamboo structure). However, the market offers very few complex bamboo products, and intensive R\&D programs are needed to overcome this barrier. Both the number of enterprises with an R\&D department and the amount of R\&D investment are far from sufficient for developing complex bamboo products.

\subsection{Production Costs (B8)}

Raw bamboo materials have competitive cost advantages because bamboo grows quickly. However, the cost advantage of bamboo materials disappears as the work required to process raw bamboo material is largely done manually, including cutting, transporting, processing, and constructing. As a result, a low efficiency and high labor costs are induced in bamboo production [23]. As bamboo has no explicit cost advantage compared with other alternative materials, its application is largely restricted. In a project led by Expert D, the cost for processed bamboo materials was four times higher than that of raw bamboo materials. The expert further pointed out another case, where a developer decided to use wood instead of bamboo to build cottages because the price of processed bamboo material was higher than wood in market quotes. The above discussion shows that high production cost is a significant barrier to the application of bamboo in the Chinese building sector.

\subsection{Education (B9)}

There are no training programs on bamboo applications for architects, engineers, or craftsmen. The market demand for bamboo products is limited in China, and neither vocational training institutions nor colleges or universities provide relevant education. As pointed out by Expert D, the number of employees engaged in bamboo construction was very small. They further shared that when their company planned to build a house and a bridge with bamboo, it was difficult to find proper local architects and craftsmen. The company had to spend a lot more to invite a bamboo craftsman from another province to lead local carpentry staff. The little education received by architects, engineers, and craftsmen about bamboo applications makes them unable to understand advantages of the material. The absence of education programs limits the cultivation of talents and, thus, hinders application of bamboo in the construction industry.

\subsection{Traditional Bias Against Bamboo Application (B10)}

By traditional perception, bamboo materials are mainly used in economically undeveloped areas for providing basic accommodation for local residents. The materials are normally put through basic 
processing; thus, the price of the material is low, but it has poor durability. As a result, bamboo sometimes is called the 'wood of the poor' [11]. With this perception, virtually no residents nowadays, both in urban and rural areas, are willing to live in bamboo buildings, as they do not want to be perceived as 'poor'. As pointed out by Expert G, when it came to bamboo building materials, customers would often consider it cheap, nondurable, and unfashionable. Actually, the durability and aesthetics of processed bamboo material have largely improved nowadays. It is traditional bias and lack of understanding of bamboo that causes customers to give up bamboo as a green building material.

\subsection{Limited Market for Bamboo Application (B11)}

Customers for bamboo materials in the construction market are limited. On one hand, customers know very little about the benefits of bamboo buildings because there is limited publicity of the materials. On the other hand, designers often do not suggest bamboo as a building material because of their limited knowledge about the materials. According to Expert $C$, there were few bamboo material markets in China, except for some places only for the trade of raw bamboo such as Luzhou in Sichuan province. It can be seen that limited knowledge and promotion of bamboo materials restrains bamboo market development.

\subsection{Certification Mechanism for Bamboo Materials (B12)}

Certification is a mechanism to certify that a certain type of material or product meets quality requirements. Currently, there are no relevant certification standards in China for bamboo material products [32]. Although bamboo is widely recognized as a green building material, it is not listed in the green building standards implemented in China. Consequently, even those in favor of green building materials will not choose bamboo, as echoed by Expert E and Expert G. Without certification, customers have no confidence in choosing bamboo for building materials.

\subsection{Code of Practice in the Bamboo Industry (B13)}

Typical codes of practice in the construction market include measures to punish companies for violation of market practice and measures to constrain unfair or illegal behaviors in the market [30]. There is no such code of practice for bamboo application in China. Without this, it is difficult to ensure healthy operation of the bamboo construction market. Expert D pointed out that enterprises did not carry out adequate bamboo corrosion treatment in order to reduce production costs. Consequently, the quality of bamboo products cannot be protected. These behaviors are often not punished because there are no regulations or codes available. According to Gresham's Law, that bad money drives out good [63], these bad-behavior enterprises disrupt the operation of the bamboo materials market. Other researchers also pointed out the importance of codes for applying bamboo materials in order to promote bamboo application [30]. In current practices in the Chinese building sector, there is no mechanism to ensure good quality bamboo material. Consequently, the application of bamboo materials is restrained.

\subsection{Incentive Policy (B14)}

It is important to introduce certain incentive policies by the government that aim at encouraging enterprises to operate their business in the bamboo material market. Expert E shared that currently there were some economic incentive measures introduced by local governments in the Chinese building sector, such as subsidies and tax refunds. However, they further pointed out few enterprises considered those incentive policies helpful because of the strict preconditions imposed by government, the long payback period of subsidies or tax refund, and the low tax refund rate. The existing incentive policy was not effective, echoed by Expert E. This constrained the application of bamboo materials as a result. 


\subsection{Technology Transfer Mechanisms (B15)}

Technology transfer is one of the most direct and effective ways to promote economic development by applying advanced technologies [30]. this mechanism consists of transferring or disseminating technology from the places of its origin to a wider distribution among more users. There are a lot of technologies developed by researchers on the application of bamboo materials, and the effective transfer of these technologies could help enterprises avoid repeated research and promote direct use of these technologies. However, as Expert E pointed out, their enterprise has no channels for establishing cooperative relations with universities where they believed mature technologies about bamboo materials were available. Their company had to spend extra time and costs on developing bamboo processing technologies if they wanted to apply these materials. It can be seen that without technology transfer mechanisms, mature technology has less chance to be applied. Repeated R\&D activity costs more resources. This concludes that the lack of a technology transfer mechanism hinders the application of bamboo in the construction industry.

\section{Integrative Analysis of the Characteristic Barriers}

Next, an integrative analysis is given on the hierarchy structure among the characteristic barriers using the ISM method and the classification on the barriers from the driving-driven perspective using the MICMAC technique.

\subsection{The Hierarchy Structure between the Characteristic Barriers}

The ISM method was used to establish a hierarchy structure between the identified 15 characteristic barriers affecting the application of bamboo materials in the Chinese building sector. The structure was helpful in understanding the interrelations among the barriers.

\subsubsection{Establishment of an Adjacency Matrix}

According to the ISM method, an adjacency matrix is used to present contextual relationships between identified barriers. Contextual relationships are usually established by collecting expert opinions [47]. In order to understand interactive relationships between barriers, a contextual relationship of "direct influence" was used to indicate that one barrier directly influenced another barrier. For example, Barrier $\alpha$ influences Barrier $\beta$, and Barrier $\beta$ influences Barrier $\gamma$. In this case, the relationship between Barrier $\alpha$ and Barrier $\beta$ is a direct influence, and the relationship between Barrier $\alpha$ and Barrier $\gamma$ is an indirect influence. On the other hand, direction of "influence" needs to be considered. For example, Barrier $\alpha$ affects Barrier $\beta$ directly, but Barrier $\beta$ may not directly affect Barrier $\alpha$.

According to principles of the ISM method, the qualitative description between barriers can be transformed into a binary matrix, called an "adjacency matrix", in which the qualitative description of the relationship between two barriers will be expressed with 1 or 0 . The rules for defining this expression are as follows:

(i) If Barrier $\alpha$ has a direct influence on Barrier $\beta$, then the $(\alpha, \beta)$ entry in the adjacency matrix will be 1 , otherwise the entry will be 0 ;

(ii) If Barrier $\beta$ has a direct influence on Barrier $\alpha$, then the $(\beta, \alpha)$ entry in the adjacency matrix will be 1 , otherwise the entry will be 0 ;

(iii) If Barrier $\alpha$ has a direct influence on Barrier $\beta$, and at the same time Barrier $\beta$ has direct influence on Barrier $\alpha$, then both the entries $(\alpha, \beta)$ and $(\beta, \alpha)$ in the adjacency matrix will be 1 .

The seven experts who participated in the interview discussions in the earlier stage were approached through emails to assist in assessing the contextual relationships between the 15 characteristic barriers. The experts conducted the pairwise comparison on the 15 barriers by responding to the question "Do you think Barrier $\alpha$ directly affect Barrier $\beta$ ?". As different experts may judge the 
relationship differently, the final results from expert opinions were based on the principle of "The minority gives way to the majority". As a result, contextual relationships between the 15 representative barriers were established in an adjacency matrix, as shown in Table 5.

Table 5. The adjacency matrix (A) between 15 representative barriers.

\begin{tabular}{cccccccccccccccc}
\hline A & B1 & B2 & B3 & B4 & B5 & B6 & B7 & B8 & B9 & B10 & B11 & B12 & B13 & B14 & B15 \\
\hline B1 & 1 & 0 & 0 & 0 & 0 & 0 & 0 & 0 & 0 & 1 & 0 & 0 & 0 & 0 & 0 \\
B2 & 0 & 1 & 0 & 0 & 0 & 0 & 0 & 0 & 1 & 0 & 0 & 0 & 0 & 0 & 0 \\
B3 & 0 & 0 & 1 & 0 & 0 & 0 & 0 & 1 & 0 & 1 & 0 & 0 & 0 & 0 & 0 \\
B4 & 0 & 0 & 0 & 1 & 1 & 1 & 0 & 0 & 1 & 0 & 0 & 1 & 1 & 1 & 1 \\
B5 & 0 & 0 & 0 & 0 & 1 & 0 & 0 & 0 & 0 & 0 & 0 & 0 & 1 & 0 & 0 \\
B6 & 0 & 0 & 0 & 0 & 0 & 1 & 1 & 1 & 1 & 0 & 0 & 0 & 0 & 0 & 0 \\
B7 & 0 & 0 & 0 & 0 & 0 & 0 & 1 & 0 & 0 & 0 & 1 & 0 & 0 & 0 & 0 \\
B8 & 0 & 0 & 0 & 0 & 0 & 0 & 0 & 1 & 0 & 0 & 1 & 0 & 0 & 0 & 0 \\
B9 & 0 & 1 & 0 & 0 & 0 & 0 & 0 & 0 & 1 & 1 & 1 & 0 & 0 & 0 & 0 \\
B10 & 0 & 0 & 0 & 0 & 0 & 1 & 0 & 0 & 1 & 1 & 1 & 0 & 0 & 0 & 0 \\
B11 & 0 & 0 & 0 & 0 & 0 & 0 & 0 & 0 & 0 & 0 & 1 & 0 & 0 & 0 & 0 \\
B12 & 0 & 0 & 0 & 0 & 1 & 0 & 0 & 0 & 0 & 0 & 0 & 1 & 1 & 0 & 0 \\
B13 & 0 & 0 & 0 & 0 & 0 & 1 & 0 & 0 & 0 & 0 & 0 & 0 & 1 & 0 & 0 \\
B14 & 0 & 0 & 0 & 0 & 0 & 1 & 0 & 0 & 0 & 0 & 0 & 0 & 0 & 1 \\
B15 & 0 & 0 & 0 & 0 & 0 & 0 & 0 & 0 & 0 & 0 & 0 & 0 & 0 & 0 & 1 \\
\hline
\end{tabular}

\subsubsection{Establishment of a Reachability Matrix}

The adjacency matrix in Table 5 demonstrated direct relationships among these 15 representative barriers. However, the adjacency matrix could not tell the indirect relationships between barriers. A reachability matrix, which was produced through conducting power iteration analyses based on the adjacency matrix, could tell both direct and indirect relationships in a matrix. A reachability matrix will be obtained when the following equation is met:

$$
\mathrm{R}=\mathrm{A}^{\mathrm{K}}=\mathrm{A}^{\mathrm{K}}+1 \mathrm{~K}>1
$$

where $\mathrm{R}$ is the reachability matrix and $\mathrm{A}$ is the adjacency matrix. The power iterations were conducted with MATLAB. As a result, the reachability matrix in this study was obtained, as shown in Table 6. The entries with the value of 1 represented that the corresponding two barriers had either direct or indirect relationships.

Table 6. The reachability matrix $(\mathrm{R})$ between 15 representative barriers.

\begin{tabular}{cccccccccccccccc}
\hline A & B1 & B2 & B3 & B4 & B5 & B6 & B7 & B8 & B9 & B10 & B11 & B12 & B13 & B14 & B15 \\
\hline B1 & 1 & 1 & 0 & 0 & 0 & 1 & 1 & 1 & 1 & 1 & 1 & 0 & 0 & 0 & 0 \\
B2 & 0 & 1 & 0 & 0 & 0 & 1 & 1 & 1 & 1 & 1 & 1 & 0 & 0 & 0 & 0 \\
B3 & 0 & 1 & 1 & 0 & 0 & 1 & 1 & 1 & 1 & 1 & 1 & 0 & 0 & 0 & 0 \\
B4 & 0 & 1 & 0 & 1 & 1 & 1 & 1 & 1 & 1 & 1 & 1 & 1 & 1 & 1 & 1 \\
B5 & 0 & 1 & 0 & 0 & 1 & 1 & 1 & 1 & 1 & 1 & 1 & 0 & 1 & 0 & 0 \\
B6 & 0 & 1 & 0 & 0 & 0 & 1 & 1 & 1 & 1 & 1 & 1 & 0 & 0 & 0 & 0 \\
B7 & 0 & 0 & 0 & 0 & 0 & 0 & 1 & 0 & 0 & 0 & 1 & 0 & 0 & 0 & 0 \\
B8 & 0 & 0 & 0 & 0 & 0 & 0 & 0 & 1 & 0 & 0 & 1 & 0 & 0 & 0 & 0 \\
B9 & 0 & 1 & 0 & 0 & 0 & 1 & 1 & 1 & 1 & 1 & 1 & 0 & 0 & 0 & 0 \\
B10 & 0 & 1 & 0 & 0 & 0 & 1 & 1 & 1 & 1 & 1 & 1 & 0 & 0 & 0 & 0 \\
B11 & 0 & 0 & 0 & 0 & 0 & 0 & 0 & 0 & 0 & 0 & 1 & 0 & 0 & 0 & 0 \\
B12 & 0 & 1 & 0 & 0 & 1 & 1 & 1 & 1 & 1 & 1 & 1 & 1 & 1 & 0 & 0 \\
B13 & 0 & 1 & 0 & 0 & 0 & 1 & 1 & 1 & 1 & 1 & 1 & 0 & 1 & 0 & 0 \\
B14 & 0 & 1 & 0 & 0 & 0 & 1 & 1 & 1 & 1 & 1 & 1 & 0 & 0 & 1 & 0 \\
B15 & 0 & 0 & 0 & 0 & 0 & 0 & 0 & 0 & 0 & 0 & 0 & 0 & 0 & 0 & 1 \\
\hline
\end{tabular}




\subsubsection{Establishment of a Hierarchy Structure}

In order to establish the hierarchy structure between the 15 barriers, level partitions of each barrier needed to be first identified. Results of the level partitions of the 15 barriers are shown in Tables 7, 8 and A1-A5, with each table including the columns of reachability set, antecedent set, intersection set, and level. The process of partition analysis is discussed as follows:

Table 7. Level 1 partition.

\begin{tabular}{|c|c|c|c|c|}
\hline Barrier & Reachability Set & Antecedent Set & Intersection Set & Level \\
\hline 1 & $1,2,6,7,8,9,10,11$ & 1 & 1 & \\
\hline 2 & $2,6,7,8,9,10,11$ & $1,2,3,4,5,6,9,10,12,13,14$ & $2,6,9,10$ & \\
\hline 3 & $2,3,6,7,8,9,10,11$ & 3 & 3 & \\
\hline 4 & $2,4,5,6,7,8,9,10,11,12,13,14,15$ & 4 & 4 & \\
\hline 5 & $2,5,6,7,8,9,10,11,13$ & $4,5,12$ & 5 & \\
\hline 6 & $2,6,7,8,9,10,11$ & $1,2,3,4,5,6,9,10,12,13,14$ & $2,6,9,10$ & \\
\hline 7 & 7,11 & $1,2,3,4,5,6,7,9,10,12,13,14$ & 7 & \\
\hline 8 & 8,11 & $1,2,3,4,5,6,8,9,10,12,13,14$ & 8 & \\
\hline 9 & $2,6,7,8,9,10,11$ & $1,2,3,4,5,6,9,10,12,13,14$ & $2,6,9,10$ & \\
\hline 10 & $2,6,7,8,9,10,11$ & $1,2,3,4,5,6,9,10,12,13,14$ & $2,6,9,10$ & \\
\hline 11 & 11 & $1,2,3,4,5,6,7,8,9,10,11,12,13,14$ & 11 & L1 \\
\hline 12 & $2,5,6,7,8,9,10,11,12,13$ & 4,12 & 12 & \\
\hline 13 & $2,6,7,8,9,10,11,13$ & $4,5,12,13$ & 13 & \\
\hline 14 & $2,6,7,8,9,10,11,14$ & 4,14 & 14 & \\
\hline 15 & 15 & 4,15 & 15 & \\
\hline
\end{tabular}

Table 8. Level 2 partition.

\begin{tabular}{ccccc}
\hline Barrier. & Reachability Set & Antecedent Set & Intersection Set & Level \\
\hline $\mathbf{1}$ & $1,2,6,7,8,9,10$ & 1 & 1 \\
$\mathbf{2}$ & $2,6,7,8,9,10$ & $1,2,3,4,5,6,9,10,12,13,14$ & $2,6,9,10$ \\
$\mathbf{3}$ & $2,3,6,7,8,9,10$ & 3 & 3 \\
$\mathbf{4}$ & $2,4,5,6,7,8,9,10,12,13,14,15$ & 4 & 4 \\
$\mathbf{5}$ & $2,5,6,7,8,9,10,13$ & $4,5,12$ & 5 & \\
$\mathbf{6}$ & $2,6,7,8,9,10$ & $1,2,3,4,5,6,9,10,12,13,14$ & $2,6,9,10$ & $\mathrm{~L} 2$ \\
$\mathbf{7}$ & 7 & $1,2,3,4,5,6,7,9,10,12,13,14$ & 7 & \\
$\mathbf{8}$ & 8 & $1,2,3,4,5,6,8,9,10,12,13,14$ & 8 & \\
$\mathbf{9}$ & $2,6,7,8,9,10$ & $1,2,3,4,5,6,9,10,12,13,14$ & $2,6,9,10$ & \\
$\mathbf{1 0}$ & $2,6,7,8,9,10$ & $1,2,3,4,5,6,9,10,12,13,14$ & $2,6,9,10$ & 12 \\
$\mathbf{1 2}$ & $2,5,6,7,8,9,10,12,13$ & 4,12 & 13 & \\
$\mathbf{1 3}$ & $2,6,7,8,9,10,13$ & $4,5,12,13$ & 14 & $\mathrm{~L} 2$ \\
$\mathbf{1 4}$ & $2,6,7,8,9,10,14$ & 4,14 & 15 & \\
$\mathbf{1 5}$ & 15 & 4,15 & & \\
\hline
\end{tabular}

\section{(1) Reachability Set}

The reachability set for one specific barrier consisted of the barrier itself and the other barriers it reached, called reachable barriers. A single barrier's reachable barriers were those with a value of 1 in the row corresponding to the concerned barrier in the reachability matrix in Table 6. For example, concerning Barrier 1, its reachable barriers included B2, B6, B7, B8, B9, B10, and B11. So, the reachability set for B1 consisted of B1, B2, B6, B7, B8, B9, B10, and B11. As a result, the reachability sets for all barriers could be obtained, as shown in the column "Reachability set" in Table 7.

(2) Antecedent Set

The antecedent set for one specific barrier consisted of the barrier itself and the other barriers which it reached, called reached barriers. A single barrier's reached barriers were those with the value of 1 in the column corresponding to the concerned barrier in the reachability matrix in Table 6 . For example, concerning Barrier 5, its reached barriers included B4 and B12. So, the antecedent set for B5 
consisted of B4, B5, and B12. As a result, the antecedent sets for all barriers were obtained, as shown in the column "Antecedent set" in Table 7.

(3) Intersection Set

The intersection set for one specific barrier consisted of the common barriers in both its reachability set and antecedent set. For example, the intersection set for B1 consisted of B1 in Table 6. As a result, the intersection sets for all barriers were obtained, as shown in the column "Intersection set" in Table 7.

(4) Identification of Level Partition between Barriers

Based on the above analysis, those barriers to which the reachability set was the same as the interaction set were identified. For example, it can be seen from Table 7 that B11 had the same reachability set and intersection set. This barrier was partitioned as a Level 1 barrier. According to the principles of ISM, the Level 1 barrier, namely B11, would be discarded from Table 7 in further analysis. The further partition process was conducted based only on the remaining barriers listed in Table 8 . By analyses of the reachability set, antecedent set, and intersection set in Table 8, Level 2 barriers will be identified, namely, B7, B8, and B15.

A similar analysis process was conducted to identify other remaining barriers at Levels 3, 4, 5, 6, and 7, as shown in in Appendix A. The results of level partitioning are summarized in Table 9.

Table 9. Summary of level partition results.

\begin{tabular}{|c|c|}
\hline Level & Barriers \\
\hline L1 & B11-Limited market for bamboo application \\
\hline L2 & $\begin{array}{l}\text { B7-Research and development (R\&D) } \\
\text { B8-Production Costs } \\
\text { B15-Technology transfer mechanism }\end{array}$ \\
\hline L3 & $\begin{array}{c}\text { B2-Knowledge about bamboo application } \\
\text { B6-Enterprise participation } \\
\text { B9-Education } \\
\text { B10-Traditional bias against bamboo application }\end{array}$ \\
\hline L4 & $\begin{array}{c}\text { B1-Durability } \\
\text { B3-Industrialization for production } \\
\text { B13-Code of practice in the bamboo industry } \\
\text { B14-Incentive policy }\end{array}$ \\
\hline L5 & B5-Standards and specifications \\
\hline L6 & B12-Certification mechanism for bamboo materials \\
\hline L7 & B4-Ineffective action by government departments \\
\hline
\end{tabular}

By using the information in Table 9, the ISM-based hierarchy structure between the 15 barriers was obtained, as shown in Figure 2.

It can be seen from Table 6 and Figure 2 that the top-level (L7) barrier 4 (Ineffective action by government department) was the most essential barrier affecting the application of bamboo materials in the Chinese building sector. In other words, the effectiveness in addressing this barrier will influence, to a large extent, application of bamboo. Barrier 4 refers to a healthy development environment for enterprises by establishing certification mechanisms (B12) and standards (B5). On the other hand, the Level 1 barrier B11 (Limited market for bamboo application) was at the bottom of the ISM hierarchy, indicating that this barrier was a superficial barrier and was affected by all other barriers. Intermediate-level barriers, like durability (B1) and industrialization for production (B3), affected consumers' traditional bias (B10) on bamboo building materials; thus, it ultimately affected market demand. 


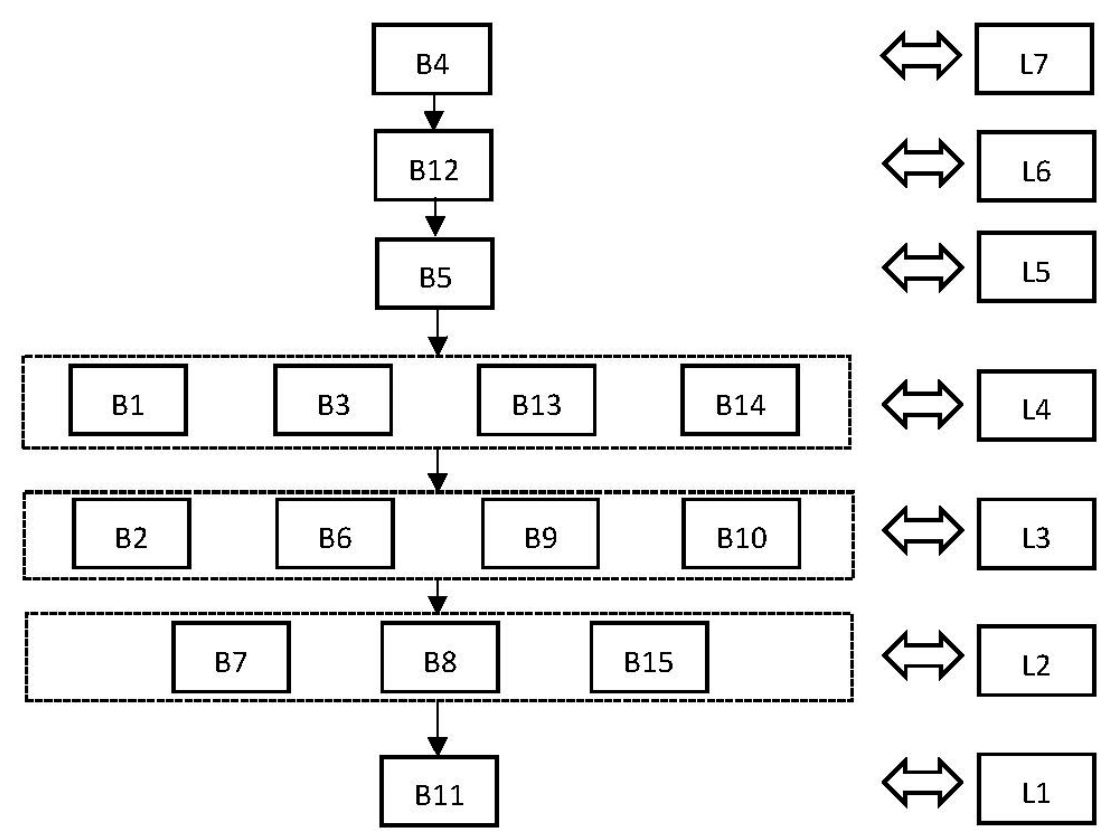

Figure 2. The hierarchy structure of the 15 representative barriers.

\subsection{Barrier Classification by the Cross-impact Matrix Multiplication Applied to Classification} (MICMAC) Method

In referring to the hierarchy structure of Figure 2, classification between the barriers can be further examined by investigating their driving power and dependence power by using the technique MICMAC. The application of MICMAC was based on the reachability matrix in Table 6 . The driving power for a particular barrier referred to the total number of the barriers affected by it, which could be calculated by adding together all the entry values of the row corresponding to the concerned barrier in the reachability matrix. For example, by referring to Table 6, the driving power of B1 was 8 . On the other hand, the dependence power (driven power) of a specific barrier referred to the total number of the barriers affecting this individual barrier, which could be calculated by adding together all the entry values of the column corresponding to the concerned barrier in the reachability matrix. For example, in Table 6, the dependence power of B1 was 1 . As a result, all barriers' driving power and dependence power can be obtained, as shown in Table 10.

Table 10. Driving power and dependence power of the representative barriers.

\begin{tabular}{cccccccccccccccc}
\hline & B1 & B2 & B3 & B4 & B5 & B6 & B7 & B8 & B9 & B10 & B11 & B12 & B13 & B14 & B15 \\
\hline Driving Power & 8 & 7 & 8 & 13 & 9 & 7 & 2 & 2 & 7 & 7 & 1 & 10 & 8 & 8 & 1 \\
Dependence Power & 1 & 11 & 1 & 1 & 3 & 11 & 12 & 12 & 11 & 11 & 14 & 2 & 4 & 2 & 2 \\
\hline
\end{tabular}

By using the information in Table 10, each barrier can be positioned in a two-dimensional diagram, as shown in Figure 3.

According to Duperrin and Godet [54], the barriers in Figure 3 were classified into four categories: autonomous barriers, dependent barriers, linkage barriers, and driving barriers.

Autonomous barriers: These barriers were weak both in driving power and driven power. They were relatively disconnected from the system they belonged to, within which they had few links. By referring to Figure 3, B15 was in this area. This indicated that the relation between B15 (Technology transfer mechanism) and other barriers was weak from the perspective of affecting bamboo material application in the Chinese building sector. 


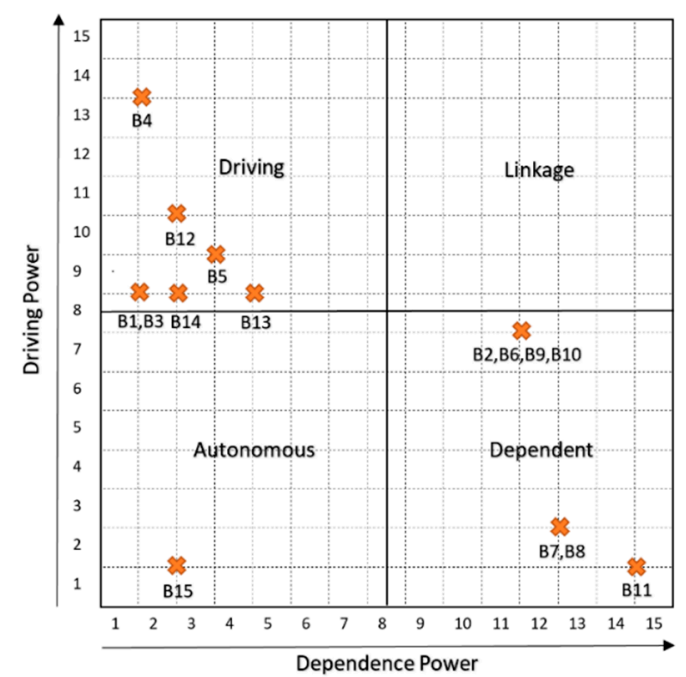

Figure 3. Driving power and dependence power of the barriers.

Dependent (driven) barriers: These barriers had weak driving power but strong dependence power, including B2, B6, B7, B8, B9, B10, and B11, as shown in Figure 3. Their effects on the application of bamboo materials depended largely on other barriers. In other words, if other barriers were addressed, these dependent barriers would be also addressed accordingly. So, it was generally accepted that these barriers were not crucial, and they were located in lower parts of the hierarchy structure.

Linkage barriers: These barriers were strong both in driving power and dependence power. They were sensitive barriers in that any action on these barriers would have effects on other barriers and also feedback on themselves. There were no linkage barriers between the identified representative barriers according to Figure 3.

Driving barriers: These barriers had strong driving power but weak dependence power, including B1, B3, B4, B5, B12, B13, and B14, as shown in Figure 3. They had the capability to influence other barriers. These barriers had strategic effects in promoting bamboo material application in the Chinese building sector, and they should be given the highest priority in designing policies for promoting bamboo application.

\section{Discussion and Conclusions}

\subsection{Discussion}

It can be observed from Figures 2 and 3 that "driving barriers" are in upper levels in the hierarchy structure, including B4 (Ineffective action by government department), B12 (Certification mechanism for bamboo materials), B5 (Standards and specifications), B1 (Durability), B3 (Industrialization for production), B13 (Code of practice in bamboo industry), and B14 (Incentive policy). This suggests that priority measures and actions should be taken to address these barriers in order to promote the application of bamboo materials. In particular, B4 should be given top priority for consideration, as it is positioned in the top level (L7) and has the largest driving power.

Furthermore, B12 (Certification mechanism for bamboo materials) and B5 (Standards and specifications) are also important driving barriers. The driving significance of these two barriers has been appreciated in previous studies, arguing that the certification mechanism, standards, and specifications for bamboo materials play important roles in the application of the materials in the construction field [11,32]. Without standards and specifications, these materials cannot be applied in the industry. However, in China, according to the discussion with Expert G, bamboo enterprises are mostly small or medium-sized, and they have little influence on establishing these standards and specifications. Therefore, it is important for the Chinese government to guide the process of establishing the standards and specifications in order to promote the application of bamboo. 
In referring to Figure 3 and Table 5, B1 (Durability) and B3 (Industrialization for production) have driving effects because they will affect B10 (Traditional bias against bamboo application) directly, and B10 is an important prerequisite for consumers to accept bamboo as building materials. Meanwhile, the promotion of bamboo in construction requires incentives (B14) such as financial subsidies, tax reductions, or low-rent workshops to encourage private capital and enterprises to join the industry. Furthermore, a mechanism of fair competition, regulation, and restriction (B13) should be created to ensure healthy development of the industry.

In referring to the seven dependent barriers (driven) (B2, B6, B7, B8, B9, B10, and B11) in Figure 3, they are superficial influence barriers. Their effects on the application of bamboo are influenced by those driving barriers. If the driving barriers can be well addressed, the performance of these dependent barriers will be improved accordingly. For example, it can be observed from Table 5 that the performance of dependent barrier B6 (enterprise participation) is largely determined by the driving barrier B4 (Ineffective action by government department). And if B4 (Ineffective action by government department) provides strong support to the dependent barrier B9 (Education), the performance of dependent barriers B2 (knowledge about bamboo application), B10 (traditional bias against bamboo application), and B11 (limited market for bamboo application) will be improved accordingly.

The barrier B15 (Technology transfer mechanism) is classified as an autonomous barrier, as shown in Figure 3. It is relatively independent, and not affected by other barriers. In other works, it is less associated with other barriers. Its driving and dependence effects are very weak. This means that technology transfer mechanisms can facilitate promotion of bamboo applications without the support of other barriers in the system. Ye et al. [30] echoed that technology transfer is a direct and effective approach to contribute to the development of a specific sector.

\subsection{Conclusions}

In the context of sustainable construction, the application of bamboo as a green material in the construction field has broad prospects. Benefits of applying bamboo as a green material have been summarized in this paper from five perspectives: large-scale and fast growth, lightweight and high strength, low-cost, environmentally friendly, and social benefits. However, because of the stagnation of bamboo material development in China, this application has encountered various barriers to overcome in the current Chinese building sector. This paper found 15 characteristic barriers. By using the ISM method, these barriers were structured in a hierarchy, which was further classified into various clusters in a two-dimensional (driving-driven power) diagram through applying the MICMAC technique.

It was found that ineffective action by the government department was the most essential barrier affecting the application of bamboo materials in the Chinese building sector. Besides that, barriers with strong driving powers for the application of bamboo materials included certification mechanisms for bamboo materials, standards and specifications, durability, industrialization for production, incentive policies, and code of practice in bamboo industry. The barriers with strong dependencies on other barriers included a limited market for bamboo application, production costs, research and development, production costs, knowledge about bamboo applications, enterprise participation, education, and traditional bias against bamboo applications.

The findings from this study provide valuable references to help decision-makers formulate effective policies for promoting the application of bamboo materials; therefore, this paper contributes to the development of sustainable construction in the context of China. The establishment of hierarchy between barriers provides essential information for identifying focal areas to be addressed. Understanding these characteristic barriers and their hierarchy structure helps top-level authorities make effective policies, standards, and regulations to guide the development of bamboo materials in the building sector. Furthermore, it can also guide practitioners for their participation in applying bamboo materials effectively. If these barriers can be addressed effectively, bamboo materials will be expected to play a very active role in practicing sustainable construction in the future Chinese building sector. Promotion of green building materials in China is not only a local issue, but it has a positive 
impact on global climate. Theoretically, this study contributes to the development of literature on the discipline of bamboo material application.

The authors acknowledge the limitations of this study. Firstly, the sample size is not quite large. Secondly, this paper focuses on the study of barriers affecting the application of bamboo materials only in the context of the Chinese building sector. Thirdly, specific solutions to mitigate barriers have yet to be studied. For future research, the quality of this study can be improved by increasing the sample size. Furthermore, future research could examine solutions for mitigating application barriers such as effective policy instruments and extending the research scope to the global level.

Author Contributions: Conceptualization, L.S. and J.Y.; methodology, X.S.; software, X.S.; validation, L.S., J.Y. and R.Z.; formal analysis, J.Y.; investigation, J.Y.; resources, C.S.; data curation, J.Y.; writing-original draft preparation, J.Y.; writing—review and editing, L.S. and R.Z.; visualization, J.Y.; supervision, L.S.; project administration, R.Z.; funding acquisition, R.Z. and L.S.

Acknowledgments: This research work was supported by the National Planning Office of Philosophy and Social Science Foundation of China (Grant No. "17ZDA062", "15BJY038" and "18BJY063" ) and the Fundamental Research Funds for the Central Universities, CQU, (Grant No. "2019 CDJSK 03 XK 24” and “2018 CDJSK 03 PT 17”).

Conflicts of Interest: The authors declare no conflict of interest.

\section{Appendix A}

Table A1. Level 3 partition.

\begin{tabular}{ccccc}
\hline Barrier & Reachability Set & Antecedent Set & Intersection Set & Level \\
\hline $\mathbf{1}$ & $1,2,6,9,10$ & 1 & 1 & \\
$\mathbf{2}$ & $2,6,9,10$ & $1,2,3,4,5,6,9,10,12,13,14$ & $2,6,9,10$ & $\mathrm{~L} 3$ \\
$\mathbf{3}$ & $2,3,6,9,10$ & 3 & 3 & \\
$\mathbf{4}$ & $2,4,5,6,9,10,12,13,14$ & 4 & 4 & \\
$\mathbf{5}$ & $2,5,6,9,10,13$ & $4,5,12$ & 5 & \\
$\mathbf{6}$ & $2,6,9,10$ & $1,2,3,4,5,6,9,10,12,13,14$ & $2,6,9,10$ & $\mathrm{~L} 3$ \\
$\mathbf{9}$ & $2,6,9,10$ & $1,2,3,4,5,6,9,10,12,13,14$ & $2,6,9,10$ & $\mathrm{~L} 3$ \\
$\mathbf{1 0}$ & $2,6,9,10$ & $1,2,3,4,5,6,9,10,12,13,14$ & $2,6,9,10$ & $\mathrm{~L} 3$ \\
$\mathbf{1 2}$ & $2,5,6,9,10,12,13$ & 4,12 & 12 & \\
$\mathbf{1 3}$ & $2,6,9,10,13$ & $4,5,12,13$ & 13 & \\
$\mathbf{1 4}$ & $2,6,9,10,14$ & 4,14 & 14 & \\
\hline
\end{tabular}

Table A2. Level 4 partition.

\begin{tabular}{ccccc}
\hline Barrier & Reachability Set & Antecedent Set & Intersection Set & Level \\
\hline $\mathbf{1}$ & 1 & 1 & 1 & L4 \\
$\mathbf{3}$ & 3 & 3 & 3 & L4 \\
$\mathbf{4}$ & $4,5,12,13,14$ & 4 & 4 & \\
$\mathbf{5}$ & 5,13 & $4,5,12$ & 5 & \\
$\mathbf{1 2}$ & $5,12,13$ & 4,12 & 12 & \\
$\mathbf{1 3}$ & 13 & $4,5,12,13$ & 13 & L4 \\
$\mathbf{1 4}$ & 14 & 4,14 & 14 & L4 \\
\hline
\end{tabular}

Table A3. Level 5 partition.

\begin{tabular}{ccccc}
\hline Barrier & Reachability Set & Antecedent Set & Intersection Set & Level \\
\hline $\mathbf{4}$ & $4,5,12$ & 4 & 4 & \\
$\mathbf{5}$ & 5 & $4,5,12$ & 5 & L5 \\
$\mathbf{1 2}$ & 5,12 & 4,12 & 12 & \\
\hline
\end{tabular}

Table A4. Level 6 partition.

\begin{tabular}{ccccc}
\hline Barrier & Reachability Set & Antecedent Set & Intersection Set & Level \\
\hline $\mathbf{4}$ & 4,12 & 4 & 4 & \\
$\mathbf{1 2}$ & 12 & 4,12 & 12 & L6 \\
\hline
\end{tabular}


Table A5. Level 7 partition.

\begin{tabular}{ccccc}
\hline Barrier & Reachability Set & Antecedent Set & Intersection Set & Level \\
\hline 4 & 4 & 4 & 4 & L7 \\
\hline
\end{tabular}

\section{References}

1. Laroque, P.P.V.M. Design of a Low Cost Bamboo Footbridge. Ph.D. Thesis, Massachusetts Institute of Technology, Cambridge, MA, USA, 2007.

2. Wallbaum, H.; Ostermeyer, Y.; Salzer, C.; Escamilla, E.Z. Indicator Based Sustainability Assessment Tool for Affordable Housing Construction Technologies. Ecol. Indic. 2012, 18, 353-364. [CrossRef]

3. Zhao, X.; Singhaputtangkul, N. Effects of Firm Characteristics on Enterprise Risk Management: Case Study of Chinese Construction Firms Operating in Singapore. J. Manag. Eng. 2016, 32, 05016008. [CrossRef]

4. CDIAC. National Emissions v1.0. 2016. Available online: https://cdiac.ess-dive.lbl.gov/GCP (accessed on 20 December 2018).

5. Nandi, J. China Represents $68 \%$ of Increase in Global $\mathrm{CO}_{2}$ Emissions, India $8 \%$ : Study. The Times of India, 2013; 15.

6. Hao, Y.; Chen, H.; Wei, Y.; Li, Y. The Influence of Climate Change on $\mathrm{CO}_{2}$ (Carbon Dioxide) Emissions: An Empirical Estimation Based on Chinese Provincial Panel Data. J. Clean. Prod. 2016, 131, 667-677. [CrossRef]

7. Archila-Santos, H.F.; Ansell, M.P.; Walker, P. Low Carbon Construction Using Guadua Bamboo in Colombia. Key Eng. Mater. 2012, 517, 127-134. [CrossRef]

8. Murphy, R.J.; Trujillo, D.; Londoño, X. Life Cycle Assessment (LCA) of a Guadua House. In Proceedings of the International Symposium of Bamboo-Guadua, Pereira, Colombia, 27 September 2004.

9. Zea Escamilla, E.; Habert, G.; Correal Daza, J.F.; Archilla, H.F.; Echeverry Fernández, J.S.; Trujillo, D. Industrial or Traditional Bamboo Construction? Comparative Life Cycle Assessment (LCA) of Bamboo-Based Buildings. Sustainability 2018, 10, 3096. [CrossRef]

10. Vogtlander, J.G.; Der Velden, N.M.V.; Der Lugt, P.V. Carbon Sequestration in LCA, a Proposal for a New Approach Based on the Global Carbon Cycle; Cases on Wood and On Bamboo. Int. J. Life Cycle Ass. 2014, 19, 13-23. [CrossRef]

11. Liu, K.; Oliver, F. An Overview of Global Bamboo Architecture: Trends and Challenges. World Archit. 2013, 3, 27-34. (In Chinese)

12. Xiao, Y.; Li, J. The State of the Art of Modern Bamboo Structures. Ind. Constr. 2015, 45, 1-6. (In Chinese)

13. Shanmugam, S.; Sun, C.; Chen, Z.; Wu, Y. Enhanced Bioconversion of Hemicellulosic Biomass by Microbial Consortium for Biobutanol Production with Bioaugmentation Strategy. Bioresour. Technol. 2019, 279, 149-155. [CrossRef]

14. Scurlock, J.; Dayton, D.C.; Hames, B. Bamboo: An Overlooked Biomass Resource? Biomass Bioenergy 2000, 19, 229-244. [CrossRef]

15. Moso, E.U. Madrid International Airport. 2016. Available online: https://www.moso.eu/en/references/ madrid-international-airport (accessed on 18 July 2018).

16. Nurdiah, E.A. The Potential of Bamboo as Building Material in Organic Shaped Buildings. Procedia-Soc. Behav. Sci. 2016, 216, 30-38. [CrossRef]

17. Jiang, F. Bamboo Houses Were Designed by Two Academicians in Nanjing, Jiangsu Province. 2009. Available online: http://news.eastday.com/m/20090613/u1a4433854.html (accessed on 2 July 2018).

18. European Commission. Sustainable Management and Quality Improvement of Bamboos and Products. 2002. Available online: https://cordis.europa.eu/project/rcn/40160_en.html (accessed on 13 August 2018).

19. European Commission. New Bamboo Engineered Bio-Material for Sustainable Building Components. 2015. Available online: https://cordis.europa.eu/project/rcn/196255/factsheet/en (accessed on 13 April 2019).

20. Samar, L. India's National Bamboo Mission. 2018. Available online: http://www.millenniumpost.in/opinion/ indias-national-bamboo-mission-308107 (accessed on 13 July 2018).

21. Liu, M. The Bamboo and Rattan Project of the 13th Five-Year Plan Was Launched. 2016. Available online: http://www.gov.cn/xinwen/2016-10/11/content_5116890.htm (accessed on 5 July 2018).

22. Jia, Z. China Forest Resources Report; China Forestry Publishing House: Beijing China, 2009. (In Chinese) 
23. Liu, L.; Wang, K.; Fei, B. Green Building Materials Began under "Bamboo"- Thinking on the Development Prospect of China's Bamboo Construction Industry. China Green Times, 23 April 2015; B02. (In Chinese)

24. Wang, J. The International Experience of Wood Structure Building Development and its Implication to China. Constr. Qual. 2017, 35, 16-20. (In Chinese)

25. Wang, Y. Study on Development Trends of Green Buildings in China. Constr. Technol. 2013, 42, 99-105. (In Chinese)

26. Civil CN Website. The Development of Green Building in China. 2016. Available online: http://www.civilcn. com/jieneng/jnlw/1468291377271932.html (accessed on 13 July 2018).

27. Beijing Times. More than 2 Billion Square Meters of New Housing Are Built in China, Accounting for More than Half the World's Total. 2015. Available online: http://finance.sina.com.cn/money/roll/20150327/ 144521827153.shtml (accessed on 15 July 2018).

28. Desalegn, G.; Tadesse, W. Resource Potential of Bamboo, Challenges and Future Directions Towards Sustainable Management and Utilization in Ethiopia. For. Syst. 2014, 23, 294-299. [CrossRef]

29. Sharma, P.; Dhanwantri, K.; Mehta, S.D.K.M. Bamboo as a Building Material. Int. J. Civ. Eng. Res. 2014, 5, 250-254.

30. Ye, Y.; Chen, Q.; Huang, X.; Tang, L. Thoughts on Bamboo and Timber Building Development in Low Carbon Economy. J. Disaster Prev. Mitig. Eng. 2010, 30 (Suppl. 1), 424-427.

31. Xu, K.; Hao, J.; Zhao, R.; Tian, L.; Zhen, J.; Ning, Z.; Zhao, L. Development and Research Status of Bamboo Applied to Building Structure. J. Bamboo Res. 2013, 32, 12-18. (In Chinese)

32. Gong, Y. Opportunity and Challenge of Wood Structure Development in China. China For. Prod. Ind. 2016, 43, 6-10. (In Chinese)

33. Fang, C.H.; Jiang, Z.H.; Sun, Z.J.; Liu, H.R.; Zhang, X.B.; Zhang, R.; Fei, B.H. An Overview on Bamboo Culm Flattening. Constr. Build. Mater. 2018, 171, 65-74. [CrossRef]

34. Yu, D.; Tan, H.; Ruan, Y. A Future Bamboo-Structure Residential Building Prototype in China: Life Cycle Assessment of Energy Use and Carbon Emission. Energy Build. 2011, 43, 2638-2646. [CrossRef]

35. Puri, V.; Chakrabortty, P.; Anand, S.; Majumdar, S. Bamboo Reinforced Prefabricated Wall Panels for Low Cost Housing. J. Build. Eng. 2017, 9, 52-59. [CrossRef]

36. Mahdavi, M.; Clouston, P.L.; Arwade, S.R. Development of Laminated Bamboo Lumber: Review of Processing, Performance, and Economical Considerations. J. Mater. Civ. Eng. 2011, 23, 1036-1042. [CrossRef]

37. Seixas, M.; Ripper, L.; Ghavami, K. Deployable Bamboo Structure for Sustainable Architecture. In Proceedings of the 15th International Conference on Non-Conventional Materials and Technologies, Pirassununga, Brazil, 23-25 November 2014.

38. Shah, R.A.; Vidyanagargujaratindia, V.; Bambhava, H.D.; Pitroda, J. Bamboo: Eco-Friendly Building Material in Indian Context. Int. J. Sci. Res. 2012, 2, 129-133. [CrossRef]

39. Opoku, D.; Ayarkwa, J.; Agyekum, K. Factors Inhibiting the Use of Bamboo in Building Construction in Ghana: Perceptions of Construction Professionals. Mater. Sci. Appl. 2016, 7, 83-88. [CrossRef]

40. Chang, F.; Chen, K.; Yang, P.; Ko, C. Environmental Benefit of Utilizing Bamboo Material Based on Life Cycle Assessment. J. Clean. Prod. 2018, 204, 60-69. [CrossRef]

41. Villegas, M. New Bamboo: Architecture and Design; Villegas Editores: Bogotá, Colombia, 2014.

42. Liu, J.; Li, S.; Gan, Q.; Zhao, Y. The Influence Barriers of Pre-Fabricated Bamboo Module Housing in Earthquake Rural Area in China. Eco-City Green Build. 2017, 22, 32-39.

43. Lugt, P.V.D.; Vogtländer, J.; Brezet, H. Bamboo, a Sustainable Solution for Western Europe—Design Cases, LCAs and Land-Use; Centre for Indian Bamboo Resource and Technology: Vansda, India, 2009.

44. Escamilla, E.Z.; Habert, G.; Wohlmuth, E. When $\mathrm{CO}_{2}$ Counts: Sustainability Assessment of Industrialized Bamboo as an Alternative for Social Housing Programs in the Philippines. Build. Environ. 2016, 103, 44-53. [CrossRef]

45. Lu, H.; Cai, C.; Zeng, X.; Campbell, D.E.; Fan, S.; Liu, G. Bamboo vs. Crops: An Integrated Emergy and Economic Evaluation of Using Bamboo to Replace Crops in South Sichuan Province, China. J. Clean. Prod. 2018, 177, 464-473. [CrossRef]

46. Sanchez-Morales, R.L.M. Reforestation with Bamboo as an Ecological Alternative on the Sustainable Production of Construction Materials and Dwellings Phase 2; Universidad Central "Marta Abreu" de Las Villas(UCLV): Santa Clara, Cuba, 2011. 
47. Attri, R.; Dev, N.; Sharma, V. Interpretive Structural Modelling (ISM) Approach: An Overview. Res. J. Manag. Sci. 2013, 2, 3-8.

48. Shen, L.; Song, X.; Wu, Y.; Liao, S.; Zhang, X. Interpretive Structural Modeling Based Factor Analysis on the Implementation of Emission Trading System in the Chinese Building Sector. J. Clean. Prod. 2016, 127, 214-227. [CrossRef]

49. Sage, A.P. Interpretive Structural Modelling: Methodology for Large-Scale Systems; McGraw-Hill: New York, NY, USA, 1977.

50. Luthra, S.; Kumar, S.; Kharb, R.; Ansari, M.F.; Shimmi, S.L. Adoption of Smart Grid Technologies: An Analysis of Interactions Among Barriers. Renew. Sustain. Energy Rev. 2014, 33, 554-565. [CrossRef]

51. Zhao, X.; Hwang, B.; Low, S.P. Developing Fuzzy Enterprise Risk Management Maturity Model for Construction Firms. J. Constr. Eng. Manag. 2013, 139, 1179-1189. [CrossRef]

52. Hwang, B.; Zhao, X.; Yu, G.S. Risk Identification and Allocation in Underground Rail Construction Joint Ventures: Contractors' Perspective. J. Civ. Eng. Manag. 2016, 22, 758-767. [CrossRef]

53. Ravi, V.; Shankar, R. Analysis of Interactions Among the Barriers of Reverse Logistics. Technol. Forecast. Soc. Chang. 2005, 72, 1011-1029. [CrossRef]

54. Duperrin, J.C.; Godet, M. Methode De Hierarchisation Des Elements D'Un Systeme; Rapport Economique Du CEA; Commissariat a L'energie Atomique: Paris, France, 1973; Volume 1, pp. 49-51.

55. Wang, G.; Wang, Y.; Zhao, T. Analysis of Interactions Among the Barriers to Energy Saving in China. Energy Policy 2008, 36, 1879-1889. [CrossRef]

56. Warfield, J.N. Developing Subsystem Matrices in Structural Modeling. Syst. Man Cybern. 1974, 4, 74-80. [CrossRef]

57. Li, X.; Zhong, Y.; Ren, H. Development Prospect of Modern Bamboo Construction in China. Wood Process. Mach. 2011, 22, 44-47.

58. Zhen, J. Study on Bamboo Building Design in Landscape Architecture. Master of Science, Fujian Agriculture and Forestry University, Fuzhou, China, 2012. (In Chinese).

59. Salzer, C.; Wallbaum, H.; Lopez, L.F.; Kouyoumji, J.L. Sustainability of Social Housing in Asia: A Holistic Multi-Perspective Development Process for Bamboo-Based Construction in the Philippines. Sustainability 2016, 8, 151. [CrossRef]

60. Wang, J. Analysis of Existing Problems and Suggestions for the Development of Wood-Structure Buildings in China. Hous. Ind. 2017, 3, 46-50. (In Chinese)

61. Hao, J.L.; Tam, V.W.Y.; Yuan, H.; Wang, J. Construction Waste Challenges in Hong Kong and Pearl River Delta Region. Int. J. Constr. Manag. 2011, 11, 37-47. [CrossRef]

62. Tam, V.W.Y.; Tam, C.M.; Chan, J.K.W.; Ng, W. Cutting Construction Wastes by Prefabrication. Int. J. Constr. Manag. 2006, 6, 15-25. [CrossRef]

63. Armitage, A. The Diseases of Money. In The World of Copernicus; New American Library: New York, NY, USA, 1974; Chapter 24; pp. 89-91. 